\title{
Multi-phenology WorldView-2 imagery improves remote sensing of savannah tree species
}

Sabelo Madonsela ${ }^{1,2}$, Moses Azong Cho ${ }^{1,2}$, Renaud Mathieu ${ }^{1,3}$, Onisimo Mutanga ${ }^{2}$, Abel Ramoelo ${ }^{1}$, Żaneta Kaszta ${ }^{4}$, Ruben Van De Kerchove ${ }^{5}$ and Eléonore Wolff ${ }^{4}$.

${ }^{1}$ Earth Observation Research Group, Natural Resources and Environment, Council for Scientific and Industrial Research (CSIR), Pretoria, South Africa

${ }^{2}$ School of Agric. Earth and Environmental Sciences, University of KwaZulu-Natal (UKZN),

Pietermaritzburg, South Africa

${ }^{3}$ Department of Geography, Geoinformatics and Meteorology, University of Pretoria, Pretoria, South

Africa

${ }^{4}$ IGEAT, Université Libre de Bruxelles (ULB), Belgium

${ }^{5}$ Unit Remote Sensing and Earth Observation Processes, Flemish Institute for Technological Research (VITO), Mol 2400, Belgium.

\section{Highlights}

- The yellow band of WorldView-2 image significantly improves spectral discrimination of savannah tree species.

- The transition to senescence phenological period is the most ideal for discriminating tree species in African savannah.

- Multi-phenology data improves tree species classification using multispectral data alone.

\section{Abstract}

Biodiversity mapping in African savannah is important for monitoring changes and ensuring sustainable use of ecosystem resources. Biodiversity mapping can benefit from multi-spectral instruments such as WorldView-2 with very high spatial resolution and a spectral configuration encompassing important spectral regions not previously available for vegetation mapping. This study investigated i) the benefits of the eight-band WorldView-2 (WV-2) spectral configuration for discriminating tree species in Southern African savannah and ii) if multiple-images acquired at key points of the typical phenological development of savannahs (peak productivity, transition to senescence) improve on tree species classifications. We first assessed the discriminatory power of WV-2 bands using interspecies-Spectral Angle Mapper (SAM) via Band Add-On procedure and tested 
the spectral capability of WorldView-2 against simulated IKONOS for tree species classification. The results from interspecies-SAM procedure identified the yellow and red bands as the most statistically significant bands ( $p=0.000251$ and $p=0.000039$ respectively) in the discriminatory power of WV-2 during the transition from wet to dry season (April). Using Random Forest classifier, the classification scenarios investigated showed that i) the 8-bands of the WV-2 sensor achieved higher classification accuracy for the April date (transition from wet to dry season, senescence) compared to the March date (peak productivity season) ii) the WV-2 spectral configuration systematically outperformed the IKONOS sensor spectral configuration and iii) the multi-temporal approach (March and April combined) improved the discrimination of tress species and produced the highest overall accuracy results at $80.4 \%$. Consistent with the interspecies-SAM procedure, the yellow $(605 \mathrm{~nm})$ band also showed a statistically significant contribution in the improved classification accuracy from WV-2. These results highlight the mapping opportunities presented by WV-2 data for monitoring the distribution status of e.g. species often harvested by local communities (e.g. Sclerocharya birrea), encroaching species, or species-specific tree losses induced by elephants.

Keywords: tree species discrimination, conservation, savannah, WorldView-2, phenology, yellow band

\section{Introduction}

Trees in African savannahs provides multiple essential resources to rural and peri-urban populations e.g. fuelwood, building material and non-timber products, such as fruits, barks and roots (Shackleton et al. 2007; Bruschi et al., 2014; Schlesinger et al. 2015) and often act as a safety net against increased poverty and food insecurity for the poorest communities (Djoudy et al 2015). Monitoring savannah tree biodiversity remains critical in order to ensure that resource use or disturbances, e.g. impact of elephants in protected areas, remains within the resilience limits of the ecosystem (Druce et al. 2008; Asner et al. 2009). Tree species abundance, distribution, and richness in savannah landscapes are impacted by land use conversion, e.g. to urban or agricultural lands, (Schlesinger et al. 2015), land management (Wessels et al. 2011; Nacoulma et al. 2011), disturbance regimes, e.g. fire, herbivory (Shackleton et al. 1994; Mudongo et al. 2016), and climate change (Stevens et al. 2014). African savannahs, as other ecosystems of the earth, are subjected to high pressure from humans and the burden remains with conservation authorities to maintain biodiversity and ensure sustainable use of biodiversity (Asner et al. 2009).

One key challenge is the lack of large scale information on tree species distribution upon which management decisions can be based to conserve biodiversity (Asner et al. 2009). The success of 
biodiversity management depends on the availability of up-to-date and spatially detailed assessments of species richness and distribution over large geographic areas (Turner et al. 2003). Spaceborne remote sensing serves as a major source of data for monitoring the Earth ecosystems especially due to its extensive spatial coverage and revisit capacity (Foody et al. 2005; Nagendra, 2001). Traditional multispectral imagery (e.g. Landsat) dominated by mixed pixels, especially in heterogeneous landscapes, and typically of poor spectral resolution (small number of bands $<10$, typically with large bandwidths, bands not strategically placed across the electromagnetic spectrum for optimally capturing biochemical composition of plants) are generally suitable for mapping broad vegetation communities from regional to landscape scales (Nagendra and Rocchini, 2008). For instance, these systems are particularly efficient in mapping species in regions dominated by stands of planted commercial species or semi-managed forests with low species diversity (Nagendra and Rocchini, 2001).

On the other hand, hyperspectral sensors sample the electromagnetic spectrum into several tenths or hundreds of contiguous bands, allowing the capture of the biochemical composition of plants which is closely linked to species identity (Asner and Martin, 2009). Typically mounted on field or airborne platforms these systems provide sub canopy pixel size and can retrieve tree species at single crown scale. Although they can image a very high number of bands, most bands are highly correlated and a few information-rich spectral regions, linked to leaf pigment and other biochemical properties, are more relevant for species discrimination (Sobhan, 2007). High spatial resolution hyperspectral systems have been reported to be an efficient approach for tree species mapping in a variety of biomes or ecosystems (Asner et al. 2008; Oldeland et al. 2010; Naidoo et al. 2012; Higgins et al. 2014). However, airborne hyperspectral tools are not widely available, especially for inventories and management applications.

The recent advancement in spectral configuration and spatial resolution of spaceborne multispectral sensors has presented new opportunities for detailed examination of biodiversity (Pu and Landry, 2012; Nagendra and Rocchini, 2008). WorldView-2 fills an important gap between the abovementioned scales. It possesses new, strategically important bands for vegetation mapping e.g. yellow, red-edge (Darvishzadeha et al. 2008; Mutanga and Skidmore, 2007) compared to well-known sensors such as Quickbird or IKONOS, and a spatial resolution $(<2 \mathrm{~m})$ compatible with the detection of single crowns. For instance, Pu and Landry (2012) reported significantly improved classifications of seven urban tree species with WorldView-2 compared to IKONOS and attributed this improvement to the better spatial resolution ( 4 to $2 \mathrm{~m}$ ) and spectral configuration of the instrument. Cho et al. (2015) mapped with $90 \%$ accuracy dominant tree species in protected subtropical coastal forests in 
South Africa. Both studies noted that the additional yellow, red-edge and NIR-2 bands on WorldView-2 sensor enhance our ability to spectrally discriminate tree species. Moreover, Cho et al. (2012), using simulated WorldView-2 data from airborne CASI-like hyperspectral data, argued that $2 \mathrm{~m}$ spatial resolution of WorldView-2 image should be suitable for mapping tree canopy greater than $6 \mathrm{~m}$ in diameter in South African savannahs. These developments in spatial and spectral resolution are pushing the boundary beyond vegetation community mapping and provide opportunities for mapping vegetation at crown scale and species-level, thus enhancing the utility of multispectral data.

Remote sensing spectral data are used to assess species diversity because tree spectral signatures are linked to their biochemical and biophysical attributes (Nagendra 2001; Asner and Marin 2009; Cho et al. 2012, 2010). For instance, the yellow and/or red-edge regions are sensitive to subtle differences in carotenoid and chlorophyll pigments amongst species, and therefore they are useful for enhancing tree species discrimination (Pu and Landry, 2012; Cho et al. 2012). However, at the same time high intra-species spectral variability weakens the assumption of unique spectral signature for each species, and this calls for innovative classification approaches (Cho et al. 2010). High intra-species spectral variability has been observed in southern African savannah setting and it originates partly from differences in within-species phenology, possibly linked to tree size, soil type, landscape position, and climatic conditions across the landscape (Archibald and Scholes 2007; Cho et al. 2010; Naidoo et al. 2012).

Recent studies have resorted to redesigning spectral libraries that account for intra-species variability in the spectral discrimination of tree species (Cho et al. 2010; Cochrane et al. 2000). Cho et al. (2010) proposed a protocol for the application of the Spectral Angle Mapper (SAM) using multiple-endmembers and achieved higher overall accuracy compared to conventional SAM. Alternatively time-series data covering different periods during phenological cycle can be used to enhance tree species discrimination (Hill et al. 2010; Gilmore et al. 2008; Key et al. 2001). Phenological changes occur throughout the growing season at different rates amongst species and data that captures these changes amplify the spectral variability between deciduous species in relation with intra-species variability (Hill et al. 2010; Key et al. 2001). This makes a multi-temporal approach towards tree species mapping in the savannah environment a topical research question. The aim of this research was to assess if i) WorldView-2 spectral configuration helps discriminating tree species in a southern African savannah environment and if ii) multiple-images acquired at key points of the typical phenological development of savannahs further improve on tree species classifications. 


\section{Study area}

The study site is situated between longitude $31^{\circ} 21^{\prime} 18.66^{\prime \prime}$ to $31^{\circ} 31^{\prime} 01.61^{\prime \prime} \mathrm{E}$ and latitude $24^{\circ} 50^{\prime} 42.61^{\prime \prime}$ to $24^{\circ} 59^{\prime} 35.04^{\prime \prime} \mathrm{S}$, covering approximately $265 \mathrm{~km}^{2}$ in the immediate vicinity of the Kruger National Park, South Africa (Figure 1). It falls in the South African Lowveld within the broader savannah biome which is characterized by the coexistence of continuous grassy vegetation layer and discontinuous woody vegetation (du Toit et al. 2003). Granite and gabbro geologies dominate in the area with vegetation communities defined by these geological structures. Gabbro patches consists of shallow to moderately deep, dark clay soils with nutritious high-bulk grasses and sparse trees and shrubs, particularly Acacia spp. Conversely, the granitic substrate consists of nutrient-poor, shallow to moderately deep sandy soils with gently undulating terrain and it sustains broad-leaved deciduous tree species upslope while fine-leaved species dominate downslope. Granitic landscapes are characterized by high species diversity and dominance of Combretum spp. (du Toit et al. 2003; Eckhardt et al. 2000). The Sabi-region, where this study was carried out, receives an annual average rainfall of $630 \mathrm{~mm}$. The average annual temperatures revolve around $22^{\circ} \mathrm{C}$ in the same period and frost is rare (du Toit et al. 2003; Eckhardt et al. 2000).

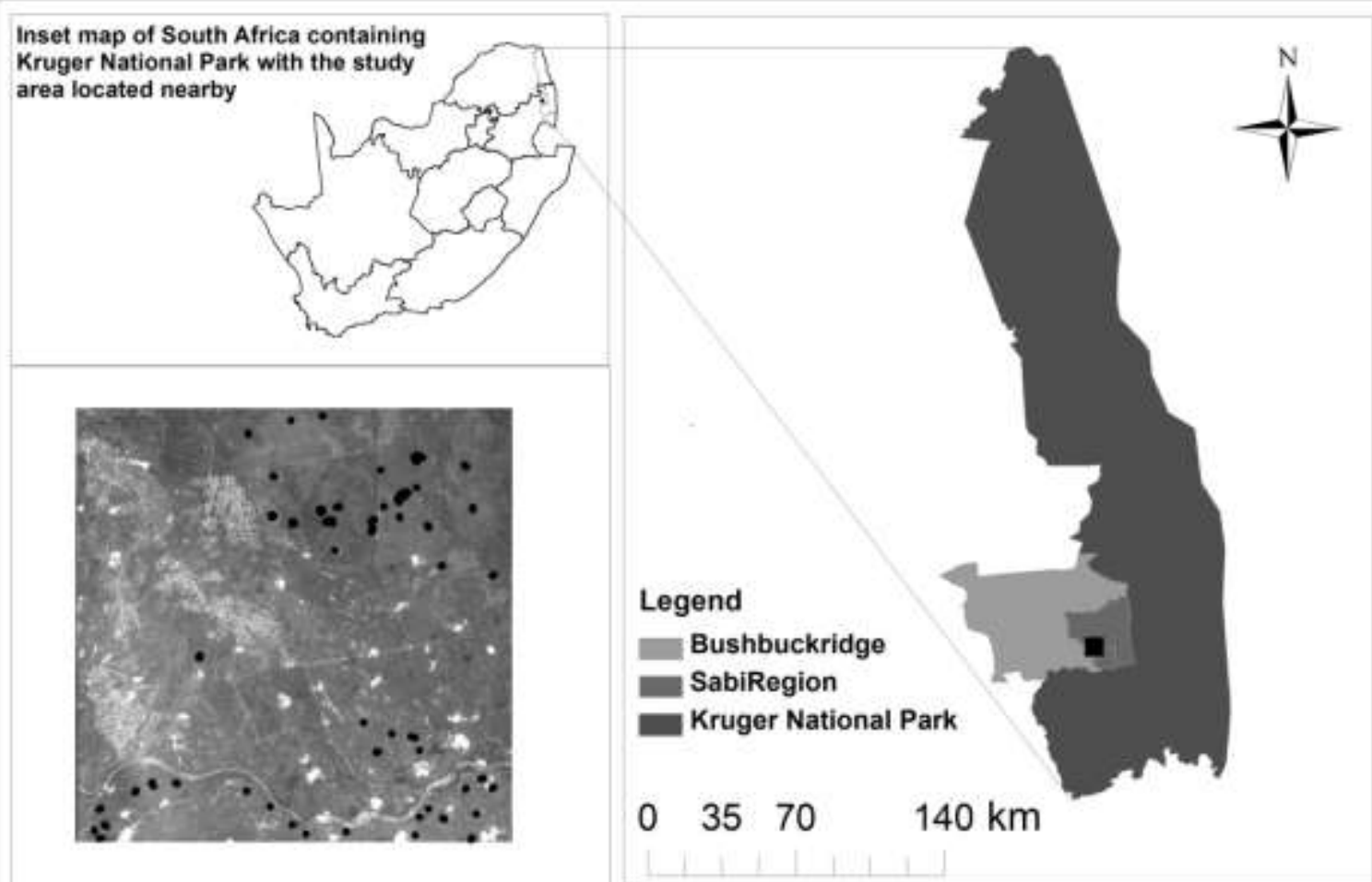

Figure 1. Study area and data collection sites shown as black dots in the lower left image. 


\section{Data and Methods}

\subsection{Remote sensing data and pre-processing}

Two WorldView-2 (hereafter called WV-2) satellite images were acquired by DigitalGlobe, Inc., USA on different dates: i) $19^{\text {th }}$ of April 2012 and ii) $7^{\text {th }}$ of March 2013 to capture different phenological periods. In southern African savannah March corresponds to the end of the rainy season with tree canopies exhibiting maximum foliage cover while April constitutes a transition period when canopies start to senesce (Cho et al. 2010). The WV-2 satellite records very high resolution (VHR) data with a swath width of $16.4 \mathrm{~km}$ and a maximum revisit period of 1.1 day. The spatial resolution at nadir is $1.84 \mathrm{~m}$ in multispectral and $0.46 \mathrm{~m}$ in panchromatic mode. WorldView-2 is amongst the few VHR multispectral sensors with eight bands situated in the visible and near-infrared regions of the spectrum: coastal blue $(400-450 \mathrm{~nm})$, blue $(450-510 \mathrm{~nm})$, green $(510-580 \mathrm{~nm})$, yellow $(580-625 \mathrm{~nm})$, red (625-690nm), red-edge (705-745nm), NIR-1(770-895nm) and NIR-2(860-1040nm).

The WV-2 images were geometrically and atmospherically corrected. Using PCl Geomatica OrthoEngine software, Rational Polynomial Coefficients based orthorectification technique with $0^{\text {th }}$, first and second order model for sensor orientation was used (Geomatica, 2013). The accuracies of the orthorectification model were assessed via a leave-one-out cross validation approach with 18 ground control points (GCPs) evenly distributed over the study area and consisting of prominent land features (e.g. road intersections). A differential GeoExplorer 2008 series GPS was used to record accurate positions of the GCPs. ATCOR-2 was used for atmospheric correction of the WV-2 images since the study area is generally flat or exhibit gentle undulating slopes (Richter and Schlapfer, 2012). Prior to image analysis, pixels covered by clouds and cloud shadows were masked out by the combination of band thresholding and manual digitizing.

\subsection{Field data}

Field data were collected in April 2012 during the programming period of the WV-2 images. Eight sites distributed across the study area were sampled purposively to cover varying degrees of tree cover (low to high tree cover) and the two main geological substrates, gabbro and granite, present in the study area. In each of these sites, a $100 \mathrm{~m}$ X $100 \mathrm{~m}$ plot was set up and all trees with diameter at breast height greater than $10 \mathrm{~cm}$ were sampled $(\mathrm{N}=273)$. Again, all sampled trees were located using a high precision GeoExplorer 600 series Global Positioning System (GPS), and the species were identified. One-second data from the Nelspruit reference station (90km from the study area) were used to post-process the GPS locations to sub-meter accuracy.

However, some of these points were later found to be located on cloud-covered parts of the image and were therefore not available for use in the analysis. To compensate for these unavailable

This article was published in JAG:

6 | P a g e http://www.sciencedirect.com/science/article/pii/S0303243417300181 
samples and maintain representativeness of each species of interest additional trees and GPS points $(\mathrm{N}=62)$ collected in the area from previous studies (Naidoo et al. 2012) were added to the tree species sample. In total 250 trees representing four species of interest were used to train and validate the classifications. The study focused on four dominant tree species that were encountered in most sampling sites: Acacia nigrescens (AN), Combretum spp. (Combretum apiculatum, Combretum zeyheri, Combretum hereroense, Combretum collinum, Combretum molle and) (COM), Sclerocarya birrea (SB) and Dichrostachys cinerea (DC) (see Table 1).

Table 1 The four tree species of interest in the study area.

\begin{tabular}{lllc}
\hline Tree species & Phenology & Significance in local context & $\begin{array}{l}\text { No. of tree } \\
\text { sampled }\end{array}$ \\
\hline $\begin{array}{l}\text { Sclerocarya } \\
\text { birrea }\end{array}$ & Deciduous & $\begin{array}{l}\text { Common tree species in SA savannah which is } \\
\text { protected by law. Its fruits are used for beer- } \\
\text { making in local communities and are also a } \\
\text { source of food for wild animals. }\end{array}$ & 70 \\
\hline $\begin{array}{l}\text { Acacia } \\
\text { nigrescens }\end{array}$ & Deciduous & $\begin{array}{l}\text { Important tree species for many browsers. } \\
\text { Nitrogen-fixing tree which increases grass }\end{array}$ & 60 \\
\hline $\begin{array}{l}\text { Combretum } \\
\text { spp. }\end{array}$ & Deciduous & $\begin{array}{l}\text { Common tree species with high density in } \\
\text { granite landscape. Often used for charcoal } \\
\text { and fuelwood production, and for many } \\
\text { medicinal purposes }\end{array}$ & 61 \\
\hline $\begin{array}{l}\text { Dichrostachys } \\
\text { cinerea }\end{array}$ & Deciduous & $\begin{array}{l}\text { Shrubby tree species often considered as an } \\
\text { encroaching species in savannah with a } \\
\text { degrading effect on rangeland quality. }\end{array}$ & 62 \\
\hline
\end{tabular}

Sources: (Shackleton and Shackleton, 2003; Naidoo et al. 2012).

\subsection{Training and validation samples}

The training and validation pixel samples were collected using region of interest (ROI) tool in ENVI 4.8. The ROI tool allowed accurate delineation of pixel defining tree canopy. The delineation of ROIs was guided by the tree GPS points which were overlaid on Worldview-2 image. During the ROIs collection process shaded and tree canopy edge pixels were avoided and only sunlit pixels were collected to define tree canopy. The number of pixels defining tree canopy varied across species due

This article was published in JAG:

http://www.sciencedirect.com/science/article/pii/S0303243417300181 
to variation in canopy size amongst tree species. Moreover, the presence of clouds in Worldview-2 image collected in April meant that some GPS points would not be used and this led to uneven distribution of training and validation pixels between the two dates. Table 2 summarizes the number of samples used for training and validation corresponding to both dates, April and March.

Table 2 Training and validation data used for tree species classification.

\begin{tabular}{lllll}
\hline & & April & March \\
& $\begin{array}{l}\text { Training } \\
\text { pixels }\end{array}$ & $\begin{array}{l}\text { Validation } \\
\text { pixels }\end{array}$ & $\begin{array}{l}\text { Training } \\
\text { pixels }\end{array}$ & $\begin{array}{l}\text { Validation } \\
\text { pixels }\end{array}$ \\
\hline $\begin{array}{l}\text { Acacia } \\
\text { nigrescens }\end{array}$ & 119 & 118 & 102 & 108 \\
$\begin{array}{l}\text { Combretum } \\
\text { spp. }\end{array}$ & 98 & 110 & 123 & 96 \\
$\begin{array}{l}\text { Dichrostachys } \\
\text { cinerea }\end{array}$ & 112 & 108 & 137 & 113 \\
$\begin{array}{l}\text { Sclerocarya } \\
\text { birrea }\end{array}$ & 123 & 92 & 87 & 103 \\
\hline
\end{tabular}

\subsection{Spectral data analysis}

The spectral signatures collected from WorldView-2 images were used to evaluate intra- and interspecies spectral variability. The evaluation was completed using the Spectral Angle Mapper (SAM). SAM is a similarity measure that quantifies the level of similarity between two spectra and is insensitive to illumination-induced differences among spectra. It quantifies the angle between two spectra $s_{i}=s_{i 1} \ldots \ldots s_{i L}$ and $s_{j}=s_{j 1} \ldots \ldots s_{j L}$

$$
\operatorname{SAM}\left(s_{i}, s_{j}\right)=\theta\left(s_{i}, s_{j}\right)=\cos ^{-1}\left(\frac{\sum_{l=1}^{L} s_{i l} s_{j l}}{\left[\sum_{l=1}^{L} s_{i l}^{2}\right]^{1} /{ }_{2}\left[\sum_{l=1}^{L} s_{j l}^{2}\right]}\right) \quad \text { Equation } 1
$$

where $L$ is the number of bands. A high angle between spectra indicates that the two species are spectrally separable (Keshava, 2004). For computing intra-species and inter-species SAM, the angle between each spectrum within species and between species was computed, respectively. Two data combinations or scenarios were tested to establish the benefits of the spectral bands pioneered in

This article was published in JAG:

http://www.sciencedirect.com/science/article/pii/S0303243417300181 
WV-2 and multiple dates in enhancing the spectral separability between species; i) all WV-2 bands for each date and ii) all WV-2 bands from the two phenological periods combined in a time-series approach.

In addition, we subjected the individual WV-2 spectral bands to further analysis through the use of the band-add-on (BAO) procedure to establish the discriminatory ability of each band. The BAO procedure is often used on high dimensionality data such as hyperspectral data (Keshava, 2004). This procedure iteratively selects bands that optimize the angular separation between spectra. The procedure adds on pairs of bands and selects those with the highest average SAM. The process is repeated until no band contributes further to the discriminatory power (Keshava, 2004). The BAO procedure was run on WV-2 bands eight times with one band excluded each time. This enabled the identification of the spectral bands with the highest discriminatory power for the species in question.

\subsection{Tree species classification}

We conducted tree species classification using a Random Forest (RF) algorithm embedded in the EnMap box (Adelabu et al. 2013). EnMap box is an auxiliary extension operating as a platformindependent processing environment for remote sensing data. This interactive data language IDLbased extension is used for classification and regression analysis of remotely sensed data (Adelabu et al. 2013). RF has been successfully applied to classify plant species using hyperspectral data in various environments (Lawrence et al. 2006; Immitzer et al. 2012). Chan and Paelinckx (2008) argued that $\mathrm{RF}$ remains the most robust machine learning algorithm due to the introduction of multiple decision trees, bootstrap aggregation and internal cross-validation concepts which improved the performance. RF is a tree-based classifier that assembles hundreds of decision trees using random subsets of training data. These decision trees are evaluated using out-of-bag estimates to establish the importance of each input (Naidoo et al. 2012; Immitzer et al. 2012; Chan and Paelinckx, 2008).

Two parameters need to be defined when running the RF algorithm, i) the number of bootstrap iterations and ii) the number of input variables at each node. We tested the bootstrap iterations from 1 to 1000 and for the input variables we used all eight bands of WV-2. The overall out-of-bag accuracy first increased abruptly and then remained almost constant beyond 105 RF trees (see Figure 2). Thus we set the number of bootstrap iterations to 105 and the number of input variables to eight bands. 


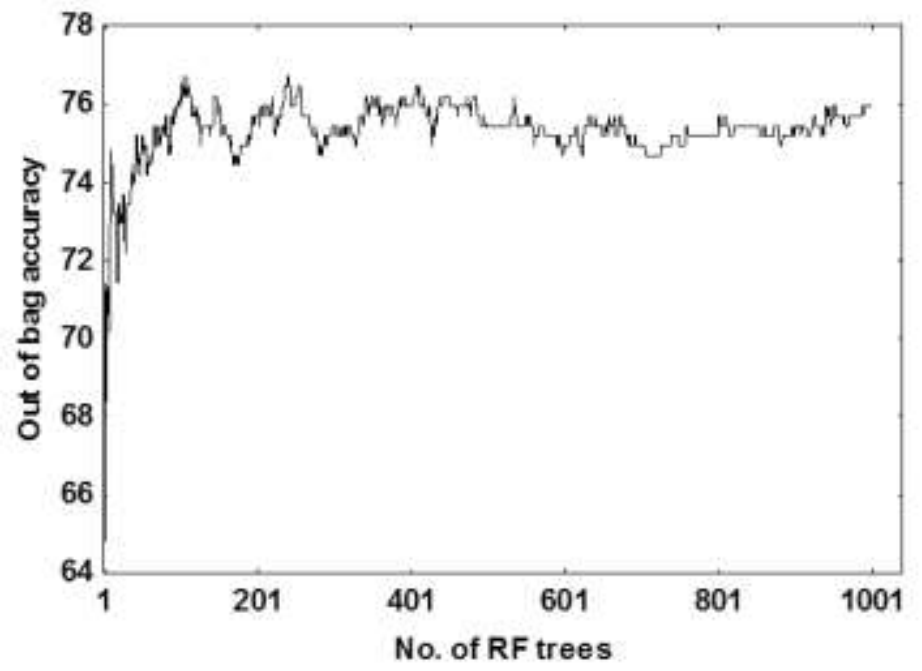

Figure 2 Out-of-bag accuracy with changing number of trees and number of random split variables at each node.

Classifications were conducted on WV-2 data independently from April 2012 and March 2013 dates, and on the combined dataset in a multi-date approach. In addition, the simulated IKONOS band configuration (blue, green, red, NIR-1) was tested as a benchmark to assess the benefit of the coastal blue, yellow, red-edge and NIR-2 on the classification performance of WV-2. Classification results were presented in a confusion matrix and interpreted according to the overall accuracy, the user's and producer's accuracy for each species. The McNemar test was used for comparing classification accuracies achieved with different band combinations. The McNemar test is a parametric test based on confusion matrices. The McNemar test employs a z-score (Equation 2) to quantify the difference between two classifications.

$$
z=\frac{\left(f_{12}-f_{21}-1\right)}{\sqrt{\left(f_{12}+f_{21}\right)}}
$$

where $f_{12}$ denotes the number of instances that were wrongly classified with all WV-2 bands but correctly classified when one band is excluded from $\mathrm{WV}-2$, and $f_{21}$ denotes the number of instances that were correctly classified with all WV-2 bands but wrongly classified when one band is excluded from WV-2. This test was preferred because it does not require independence of the sample datasets used for the two classifications (Bostanci and Bostanci, 2013), as it is the case for other tests such as the Kappa test (Foody, 2004). The classifications used the same samples as to avoid differences induced by sampling variability. 


\section{Results}

\subsection{WV-2 discriminatory power for tree species}

Generally, the tree canopy spectra for each species exhibited similar levels of intraspecies-SAM in both April and March datasets (Figure 3). However, the average intraspecies-SAM were slightly higher in March compared to April data with the exception of Acacia nigrescens. Acacia nigrescens had the highest intra-species variability in April data and this was linked to the geological formation in which the species was found. Acacia nigrescens sampled on gabbro soils often showed higher reflectance in the green, and yellow to red regions, compared to those sampled on granite soils (Figure 4; difference statistically significant, $p=0.025873$ using one-way analysis of variance for average reflectance in these three bands). In March data Dichrostachys cinerea showed the highest intra-species variability while Combretum spp. showed the lowest intra-species variability in both dates.
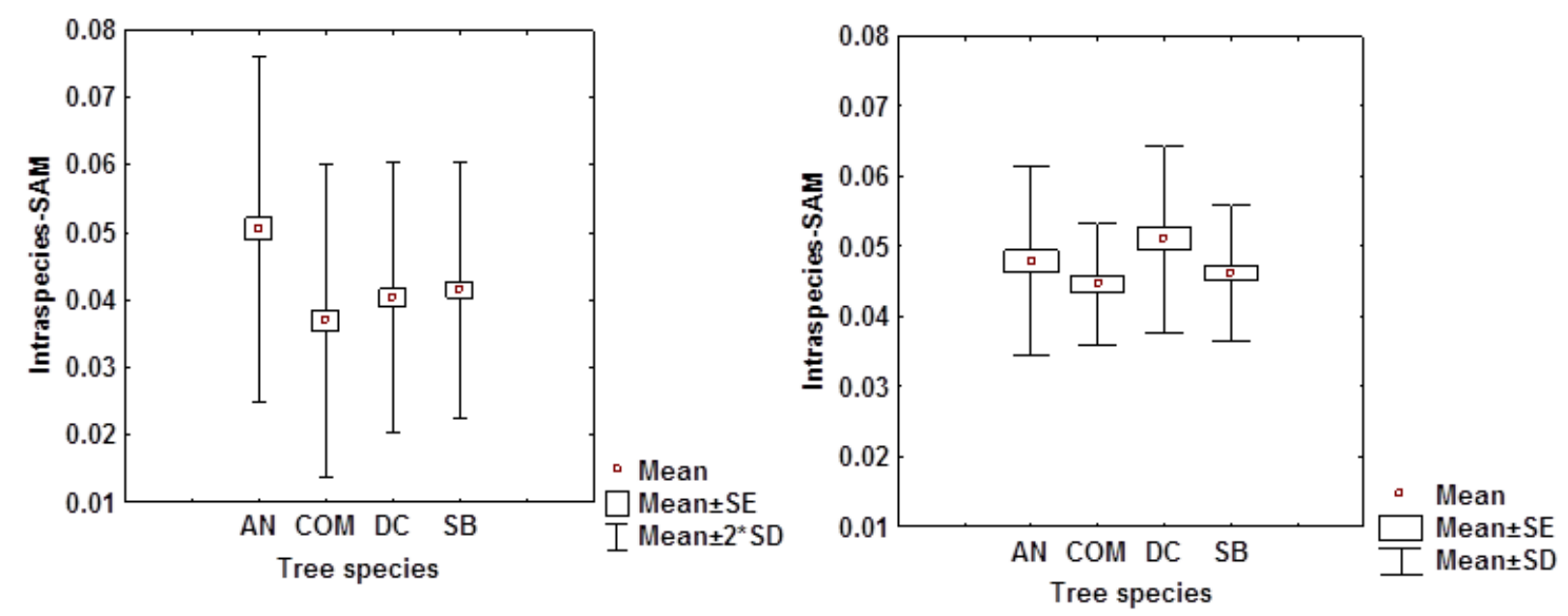

Figure 3 Intraspecies-SAM. Left: April data, and Right: March data.

The April date achieved a higher interspecies-SAM than March ( $p=0.000558, f=12.01$; using oneway analysis of variance) (see Figure 5). Therefore, tree species are more separable in April during the transition period to senescence than in March, and the former season appears to be the most suitable for discriminating tree species using WorldView-2 data. Acacia nigrescens and Combretum spp. were the most spectrally separable species in both dates. Dichrostachys cinera and Sclerocharya birrea were the least spectrally separable species in April while Acacia nigrescens and Sclerocharya birrea were the least spectrally separable in March. The time-series data achieved the highest interspecies-SAM compared to individual dates $(p=0.016646938, f=8.24)$ (see Figure 5$)$. When considering March and April data together Acacia nigrescens and Combretum spp. remained the most separable pair of species, while the least separable was found to be Dichrostachys cinera and Combretum spp. 

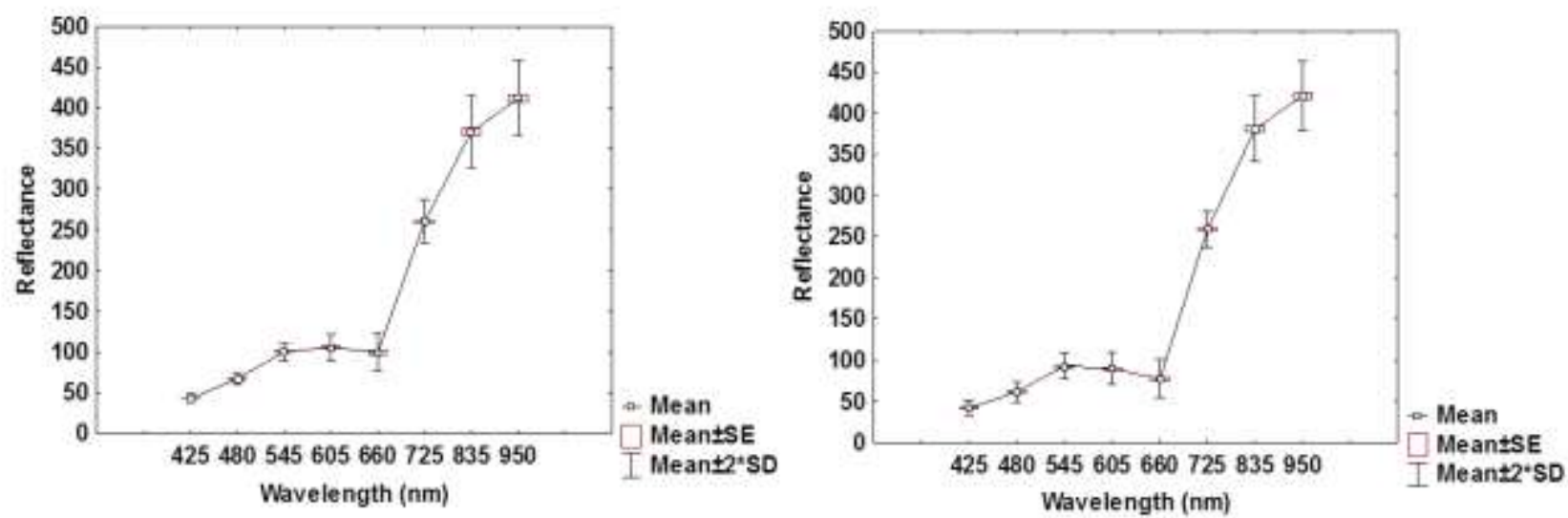

Figure 4 Spectral reflectance of Acacia nigrescens found on different geological background. Left: Acacia nigrescens found on gabbro soil, Right: Acacia nigrescens found granite soil.

The BAO procedure results identified the yellow $(605 \mathrm{~nm})$ and red $(660 \mathrm{~nm})$ bands as the most influential bands in the species discriminatory power of the WV-2 data captured during the senescing phenological period. ANOVA results are presented in Table 3 below. Using the interspecies-SAM results from the eight WV-2 band combination as a benchmark, the exclusion of either of the two bands significantly decreased the interspecies-SAM ( $p=0.000251$ and $p=0.000039$ respectively). Meanwhile, the exclusion of NIR-1 (835 nm) and NIR-2 (960 nm) bands individually, from the WV-2 band combination increased the interspecies-SAM and the increase in spectral angle was statistically significant ( $p=0.0000928$ and $p=0.000232$ respectively). The exclusion of the rededge $(725 \mathrm{~nm})$ showed insignificant changes $(p=0.145717)$ on interspecies variability. The exclusion of coastal $(425 \mathrm{~nm})$, blue $(480 \mathrm{~nm})$ and green $(545 \mathrm{~nm})$ bands did not impact significantly on the interspecies-SAM.

In March, which represents the peak of productivity season, the BAO procedure identified blue $(480 \mathrm{~nm})$, green $(545 \mathrm{~nm})$, yellow $(605 \mathrm{~nm})$ and red $(660 \mathrm{~nm})$ bands as the most important bands for discriminating tree species. ANOVA results are presented in Table 4 below. Yet again, using interspecies-SAM results from the eight WV-2 band combination as a benchmark, the exclusion of the blue, green, yellow and red bands individually from the WV-2 band combination led to a significant decline in interspecies-SAM $(p<0.05)$. Comparable with April data, the individual exclusion of NIR-1 (835nm) and NIR-2 (950nm) significantly increased interspecies-SAM ( $p=0.0000351$ and $p=0.0000402$ respectively). The exclusion of coastal $(425 \mathrm{~nm})$ and red-edge $(725 \mathrm{~nm})$ bands individually did not show any statistically significant changes on the interspeciesSAM. 

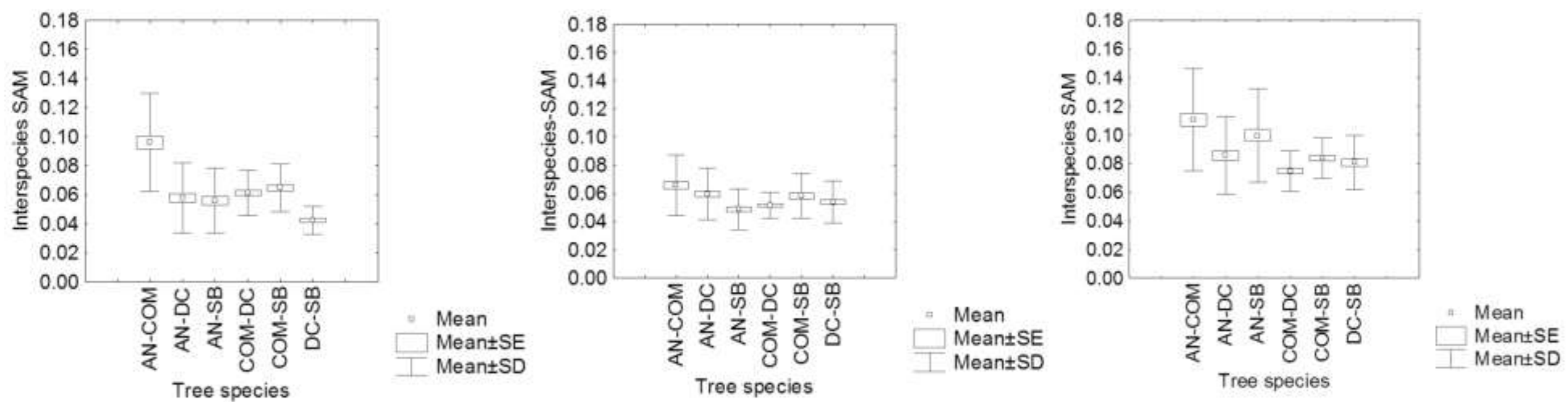

Figure 5 Interspecies-SAM from different dates and time-series dataset. Right: April data; middle: March data and left: April-March combined in a time-series approach. 
Table 3 ANOVA results: interspecies-SAM observed with stepwise exclusion of WV-2 bands via BAO procedure April date.

\begin{tabular}{llll}
\hline WV-2 band excluded & F-stats & P-value & F crit \\
\hline Coastal blue & 0.645458 & 0.422004 & 3.854299 \\
Blue & 2.877105 & 0.090276 & 3.854299 \\
Green & 2.957948 & 0.085883 & 3.854299 \\
Yellow & 13.53715 & 0.000251 & 3.854299 \\
Red & 30.80934 & 0.0000399 & 3.854299 \\
Red-edge & 2.121077 & 0.145717 & 3.854299 \\
NIR-1 & 15.45058 & 0.0000928 & 3.854299 \\
NIR-2 & 46.11867 & 0.0000232 & 3.854299 \\
\hline
\end{tabular}

Table 4 ANOVA results: interspecies-SAM observed with stepwise exclusion of WV-2 bands via BAO procedure March date.

\begin{tabular}{llll}
\hline WV-2 band excluded & F-stats & P-value & F crit \\
\hline Coastal blue & 1.676775 & 0.195719 & 3.852852 \\
Blue & 4.964416 & 0.026145 & 3.852852 \\
Green & 8.085053 & 0.004574 & 3.852852 \\
Yellow & 18.45811 & 0.0000195 & 3.852852 \\
Red & 37.88875 & 0.000117 & 3.852852 \\
Red-edge & 0.845914 & 0.357982 & 3.852852 \\
NIR-1 & 30.99207 & 0.0000351 & 3.852852 \\
NIR-2 & 44.81688 & 0.0000402 & 3.852852 \\
\hline
\end{tabular}

\subsection{Tree classification: $\mathrm{WV}-2$ and multi-phenological data}

Consistent with the interspecies-SAM results, the April date achieved higher classification accuracy than the March date (see Table 5). Producer's and user's accuracies for Combretum spp., Acacia nigrescens and Dichrostachys cinerea were all above 70\% in April (see Table 5). Only the producer's accuracy for Sclerocharya birrea was particularly low for both dates due to spectral confusion with Combretum spp., Acacia nigrescens and Dichrostachys cinerea. Low producer's accuracies for Acacia nigrescens and Dichrostachys cinerea were also observed in March. The time-series data improved producer's and user's accuracies of all species including that of Sclerocharya birrea and Dichrostachys cinerea which are difficult to discriminate using spectral data alone (Naidoo et al. 2012), and were also difficult to discriminate with single dates. Sclerocharya birrea and Dichrostachys cinerea produced the lowest interspecies-SAM in both April and March dates. However the spectral separability was improved with multi-date data (see figure 5). The time-series 
data achieved the highest overall classification accuracy (see Table 5) and this was consistent with interspecies-SAM results.

Table 5 Producer's and user's accuracies from single Worldview-2 data and time-series data.

\begin{tabular}{l|rr|rr|rr}
\hline & \multicolumn{1}{c}{ April data } & \multicolumn{3}{c}{ March data } & \multicolumn{2}{c}{ Time-series data } \\
\hline Classes & Producer's & User's & Producer's & User's & Producer's & \multicolumn{1}{l}{ User's } \\
& accuracy & accuracy & accuracy & accuracy & accuracy & accuracy \\
Com & $94.50 \%$ & $86.60 \%$ & $83.60 \%$ & $81.40 \%$ & $96.50 \%$ & $100 \%$ \\
AN & $79.60 \%$ & $74.00 \%$ & $65.20 \%$ & $76.20 \%$ & $95.00 \%$ & $80.80 \%$ \\
SB & $44.50 \%$ & $69.40 \%$ & $55.40 \%$ & $68.00 \%$ & $66.60 \%$ & $61.50 \%$ \\
DC & $81.40 \%$ & $72.10 \%$ & $79.60 \%$ & $61.80 \%$ & $60.00 \%$ & $77.70 \%$ \\
& & & & & & \\
\hline $\begin{array}{l}\text { Overall } \\
\text { classification } \\
\text { accuracy }\end{array}$ & $76.4 \%$ & $72.9 \%$ & & & \\
\hline
\end{tabular}

\subsection{Comparison between WV-2 and simulated IKONOS}

The WV-2 band combination achieved a significantly higher classification accuracy compared to the classification based on simulated IKONOS bands (McNemar test, $z_{o b t}=5.833 ; z_{c r i t}=3.841$ ) (see Table 6). To further investigate the benefits of the new bands featuring in WV-2 (coastal, yellow, red-edge and NIR-2) we ran a set of classifications excluding these bands one by one only for the April date. The following overall classification accuracies were obtained and, consistent with the BAO procedure, decreased from $76.4 \%$ with all WV-2 bands: $70.3 \%$ without coastal band centred at $425 \mathrm{~nm}$ (significant, McNemar test, $z_{o b t}=4.269 ; z_{c r i t}=3.841$ ), 69.6\% without yellow band centred at $605 \mathrm{~nm}$ (significant McNemar test, $z_{o b t}=4.269 ; z_{c r i t}=3.841$ ), 70.7\% without red-edge band centred at $725 \mathrm{~nm}$ (non-significant McNemar test, $z_{o b t}=3.252 ; z_{\text {crit }}=3.841$ ) and $70.3 \%$ without NIR-2 band centred at $950 \mathrm{~nm}$ (non-significant McNemar test, $z_{o b t}=3.608 ; z_{c r i t}=3.841$ ).

Table 6 Producer's and user's accuracy from WV-2 and simulated IKONOS.

\begin{tabular}{lllll}
\hline & WV-2 & \multicolumn{3}{c}{ IKONOS } \\
\hline Classes & $\begin{array}{l}\text { Producer's } \\
\text { accuracy }\end{array}$ & $\begin{array}{l}\text { User's } \\
\text { accuracy }\end{array}$ & $\begin{array}{l}\text { Producer' } \\
\text { accuracy }\end{array}$ & $\begin{array}{l}\text { User' } \\
\text { accuracy }\end{array}$ \\
\hline Com & $94.50 \%$ & $86.60 \%$ & $82.88 \%$ & $90.00 \%$ \\
AN & $79.60 \%$ & $74.00 \%$ & $70.10 \%$ & $66.66 \%$ \\
SB & $44.50 \%$ & $69.40 \%$ & $52.08 \%$ & $51.02 \%$ \\
DC & $81.40 \%$ & $72.10 \%$ & $61.70 \%$ & $59.18 \%$ \\
Total & & & & \\
Overall Accuracy & $76.40 \%$ & & $67.33 \%$ & \\
Overall Kappa & $68.30 \%$ & & $56.44 \%$ & \\
\hline
\end{tabular}


Figure 6 presents a species maps produced using the April date which had the higher classification accuracy. The species maps are consistent with our field knowledge, Combretum species dominating in the granite soils while Acacia nigrescens dominate on gabbro soils. The distribution of Sclerocharya birrea was underestimated due to misclassification with other species.

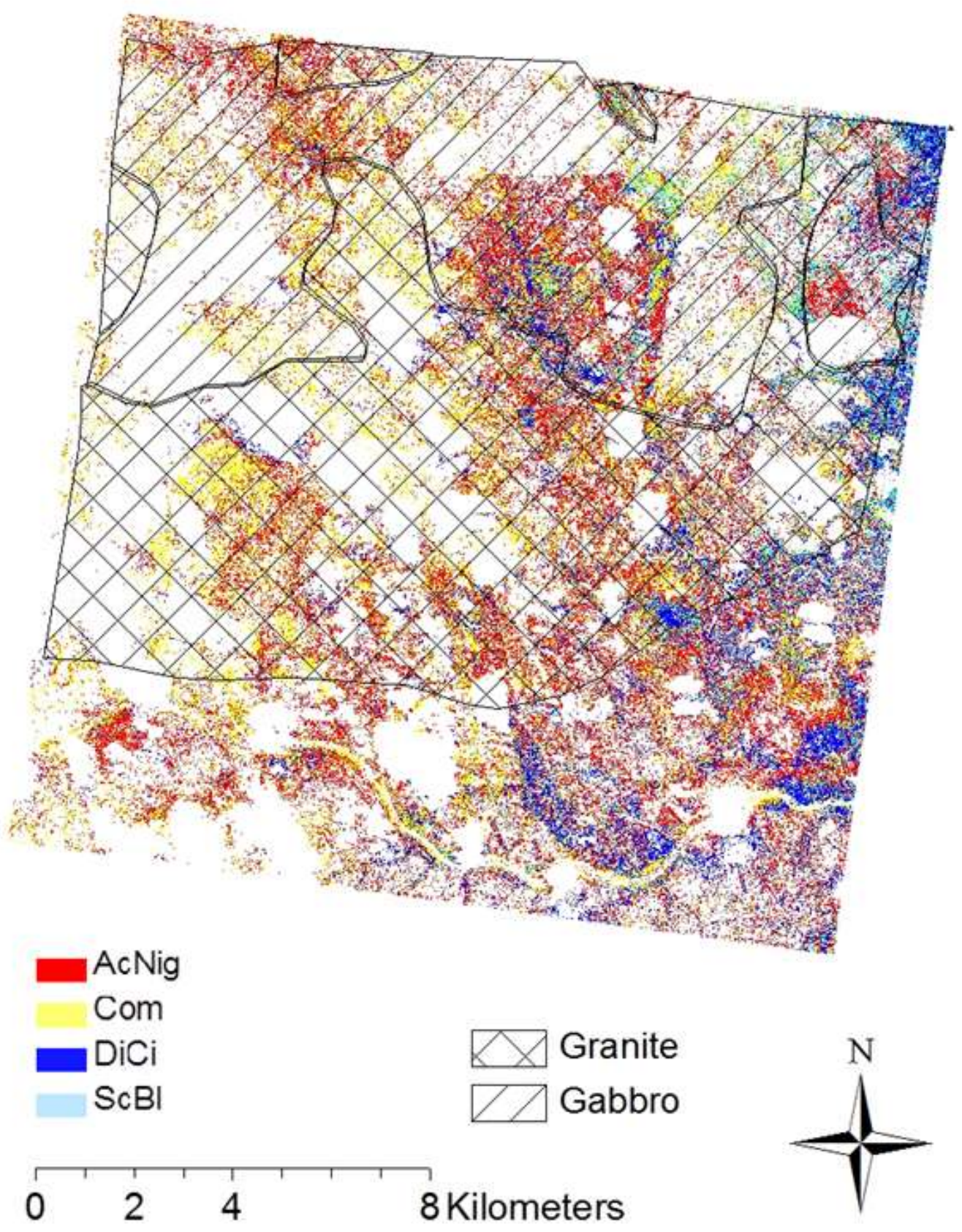

Figure 6 Tree classification map produced with April date. 


\section{Discussion}

High interspecies spectral variability and low intraspecies spectral variability is the key requirement for successful classification of tree species (Castro-Esau et al. 2006). This necessitates the identification of the phenological period at which the spectral variability between species is high. The results of this study identified April as the best single date compared to March for tree species discrimination in southern African savannah. The month of April is a transition phase from full green canopy to senescence (Cho et al. 2010), prior to leaf shedding, when differences in leaf pigments are maximized. In addition, phenological changes vary between species (Gilmore et al. 2008) and are more pronounced during transition periods compared to periods of peak or low productivity.

Optimal phenology enhances spectral discrimination of tree species (Hill et al. 2010; van Deventer et al. 2013). Combretum spp had the highest producer's and user's accuracies compared to other species and this may be attributed to its distinct phenology. When WV-2 image was collected in April 2012 , Combretum spp was still very green while others were towards senescence stage, hence it was easily discriminated from other species with very minimal misclassification. Acacia nigrescens in particular was at an advanced senescence stage and the two species (Acacia nigrescens and Combretum spp) had the highest interspecies-SAM, and consequently lower misclassification between them. Sclerocharya birrea had the lowest producer's accuracy, and since it was often confused with Dichrostachys cinerea and Combretum spp, the lower producer's accuracy may be associated with the general misclassification of tall trees as short trees observed by Cho et al. (2012). Moreover, a study by Naidoo et al. 2012 had used a hybrid approach where hyperspectral data was combined with LiDAR data to improve the classification accuracy of Sclerocharya birrea. However, the financial cost associated with such approach remains prohibitive. It also necessitates sound technical expertise which may not be readily available in developing countries.

Overall the high interspecies-SAM variability in April is linked to differential drying and senescing patterns in the landscape, controlled by rainfall patchiness and soil variability along catenas. In contrast, the March data centred on the peak productivity and wet period (higher moisture level in the landscape) captured minor differences in tree phenological states, which are associated with lower interspecies separability (Cho et al. 2012). These observations support the assertion made by Hill et al. (2010) that the ability to discriminate tree species is higher with data captured at the start or the end of the growing season than mid-summer, which is reported to have low interspecies separability. High interspecies variability as observed from April data mitigates the effect of intraspecies variability. For instance Acacia nigrescens, which had high intraspecies-SAM, was classified with high producer's and user's accuracies. 
Nonetheless, the highest tree species discrimination was achieved with time-series data because it captured phenological change between species across images (Hill et al. 2010). The time-series approach used here enhanced interspecies variability and improved the producer's and user's accuracies of all tree species. These improvements support the literature (Hill et al. 2010; Gilmore et al. 2008), that spectral variability amongst species is enhanced when using time-series data due to variation in the rate of the phenological changes between tree species (Hill et al. 2010; Gilmore et al. 2008). Heidi et al. (2013) also documented an improved tree species discrimination using multiseasonal data in iSimangaliso wetland, South Africa. It is therefore consistent with the literature that our time-series data capturing these phenological changes have shown the highest interspeciesSAM.

The comparative analysis of classification results from WV-2 and IKONOS showed a statistically significant difference, with higher classification accuracies produced with WV-2. This can be attributed to the improved spectral configuration of WV-2. The yellow (605 nm) and coastal blue bands $(425 \mathrm{~nm})$ in particular, were found to have a significant influence on the species discriminatory ability of WV-2, compared to the red-edge and NIR-2 bands during the April period. The contribution of the yellow band may be reinforced by the phenological period at which the April image was acquired. The transition towards senescence period is characterized by a growing concentration of carotenoid (Gitelson et al. 2002; Zur et al. 2000), which is detectable in the yellow region, prior to leaf shedding. This finding was previously reported by Cho et al. (2012), who noted a higher influence from the yellow band on the performance of tree species classification using WV-2 data simulated from airborne hyperspectral data, also during the senescence period and in the same region. In addition, Pu and Landry (2012) observed improved tree species classification in an urban context in Florida, USA using WV-2 data and attributed it to the addition of the yellow, red-edge and NIR-2 bands. Overall, the study noted a consistent decline in overall classification accuracy when removing individually each additional WV-2 bands, and a significant contribution of the yellow and NIR-2 bands to interspecies spectral variability, suggesting the importance of all four additional bands in the overall performance of WV-2 image over IKONOS.

The approach proposed here demonstrates good prospect for community-scale vegetation mapping in southern African savannah, e.g. broad versus fine leaves species. For instance, broad leaves species such as Combretum spp are particularly targeted by elephants, and are a concern for conservation (Baxter et al. 2003; Druce et al. 2008). In addition, the improved discrimination of Sclerocharya birrea from Dichrostachys cinerea with time-series data, provides an opportunity to establish and monitor the distribution of Dichrostachys cinerea, which is a problematic bush 
encroachment species. Dichrostachys cinerea is often confused with Sclerocharya birrea, thus undermine the effort to monitor its distribution.

\section{Conclusion}

The findings of this study demonstrate the benefits of the eight-band WV-2 spectral configuration for tree species classification. We conclude that the classification accuracy of key tree species in African savannah is improved using WV-2 images compared to a more traditional IKONOS-like blue, red, green, NIR spectral configuration. Improvement in classification accuracy demonstrates the spectral benefits of the new bands pioneered on the WV-2 sensor. The yellow band (605 nm) and coastal band $(425 \mathrm{~nm})$ in particular were statistically significant in their contribution towards improved tree species classification. Moreover, the use of multiple images acquired at key points of phenological development of savannah tree species improved tree species classification beyond what can achieved using individual dates. Each tree species achieved higher user's and producer's accuracies including Sclerocharya birrea and Dichrostachys cinerea, which were reported by Naidoo et al. (2012) as particularly spectrally confused. Importantly, the multi-temporal approach revealed that the transition period from green canopy to senescence provides better opportunity for tree species mapping in southern African savannah than the peak productivity period. Future research that aims to classify savannah vegetation according to dominant tree species or species functional types (deciduous or evergreen) may benefits from these findings. Furthermore, future studies on the spectral significance of the additional WV-2 bands should use data acquired during the leaf-up period to document their importance throughout the growing season. Overall, the study highlights the opportunities available to biodiversity conservation managers for monitoring the distribution of e.g. encroaching species (e.g. Dichrostachys cinerea), economically viable tree species used by local communities (e.g. Sclerocharya birrea) and species-specific tree losses induced by elephants.

\section{Acknowledgements}

This study was made possible by the funding provided by the BELSPO / Research Programme for Earth observation STEREO II (contract N SR/11/153) project GRAZEO “Grazing suitability indicators from Earth Observation to improve buffalo-cattle contact risk models". We also would like to thank the South Africa's National Research Foundation (NRF) and the Applied Center for Climate and Earth Science Systems (ACCESS) for financial support to conduct this research. Furthermore we thank Oupa Malahlela, Laven Naidoo, Russell Main, Patrick Ndlovu and Mightyman Mashele for their assistance during field work. 


\section{Reference}

Archer, S., Boutton, T.W. and Hibbard, K.A., 2001. Trees in grasslands: biogeochemical consequences of woody plant expansion, pp. 115-137. In: Global Biogeochemical Cycles in the Climate System (Schulze, E.D., Harrison, S.P., Heimann, M., Holland, E.A., Lloyd, J., Prentice, I.C. and Schimel, eds). Academic Press, San Diego.

Asner, G.P., Jones, M.O., Martin, R.E., Knapp, D.E. and Hughes, R.F., 2008. Remote sensing of native and invasive species in Hawaiian forests. Remote Sensing of the Environment Vol. 112 (5), pp. 19121926.

Baxter, P.W.J., 2003. Modelling the impact of the African elephant, Loxodonta Africana, on woody vegetation in semi-arid savannas. PhD Dissertation. University of Carlifonia, Berkeley, Carlifonia, USA.

Bostanci, B. and Bostanci, E., 2013. An evaluation of classification algorithms using McNemar's test.In: Proc. Seventh International Conference on Bio-Inspired Computing. Theories and Applications (BIC-TA'12), Advances in Intelligent Systems and Computing 201, pp.15-26, Springer, India.

Bruschi, P., Mancini, M., Mattioli, E., Morganti, M. and Signorini, M.A., 2014.Traditional uses of plants in a rural community of Mozambique and possible links with Miombo degradation and harvesting sustainability.Journal of Ethnobiology and Ethnomedicine Vol. 10 (59), pp 1-22.

Castro-Esau, K.L., Sanchez-Azofeifa, G.A., Rivard, B., Wright, S.J. and Quesada, M., 2006. Variability in leaf optical properties of Mesoamerican trees and the potential for species classification. Americal Journal of Botany Vol. 93(4), pp. 517-530.

Chan, J.C. and Paelinckx, 2008. Evaluation of Random Forest and Adaboost tree-based ensemble classification and spectral band selection for ecotope mapping using airborne hyperspectral imagery. Remote Sensing of Environment Vol. 112, pp. 2999-3011.

Cho, M.A., Debba, P., Mathieu, Naidoo, L., van Aardt J. and Asner, G.P., 2010. Improving discrimination of savannah tree species through a multi-endmember spectral angle mapper approach: canopy-level analysis. IEEE Transactions on Geoscience and Remote Sensing Vol. 48(11), pp. 4133-4142.

Cho, M.A., Mathieu, R., Asner, G.P., Naidoo, L., van Aardt, J., Ramoelo, A., Debba, P., Wessels, K., Main, R., Smit, I.K.J. and Erasmus, B., 2012. Mapping tree species composition in South Africa savannas using an integrated airborne spectral and Lidar system. Remote Sensing of Environment Vol. 125, pp. 214-226.

Clark, M.L., Roberts, D.A. and Clark, D.B., 2005. Hyperspectral discrimination of tropical rain forest tree species at leaf to crown scales. Remote Sensing of Environment Vol. 96, pp. 375-398.

Colgan, M.S., Asner, G.P., Levick, S.R., Martin, R.E. and Chadwick, O.A., 2012. Topo-edaphic controls over woody plant biomass in South African savannas. Biogeosciences Vol. 9, pp. 1809-1821. 
Darvishzadeha, R., Skidmore, A., Schlerf, M., Atzberger, C., Corsi, F. and Moses Cho., 2008.LAI and chlorophyll estimation for a heterogeneous grassland usinghyperspectral measurements. ISPRS Journal of Photogrammetry \& Remote Sensing Vol. 63 (4), pp409-426.

Datt, B., 1999. Remote sensing of water content in Eucalyptus leaves. Australian Journal of Botany Vol. 47, pp. 909-923.

Djoudy H., Vergles E, Blackie RR., Koffi Koame C., Gautier D., 2015. Dry forests, livelihoods and poverty alleviation: understanding current trends. International Forest Review Vol. 17(S2), pp. 54-69.

Druce, D.J., Shannon, G., Page, B.R., Grant, R. and Slotow, R., 2008. Ecological thresholds in the savanna landscape: developing a protocol for monitoring the change in composition and utilisation of large trees. PLOS ONE 3(12), pp. 1-8.

du Toit, J.T., Biggs, H.C., Rogers, K.H., 2003. The Kruger Experience: ecology and management of savanna heterogeneity. London: Island Press.

Eckhardt, H.C., van Wilgen, B.W. and Biggs, H.C., 2000. Trends in woody vegetation cover in the Kruger National Park, South Africa, between 1940 and 1998. African Journal of Ecology Vol. 38, pp. 108-115.

Foody, G.M., Atkinson, P.M., Gething, P.W., Ravenhill, N.A. and Kelly, C.K., 2005.Identification of specific tree species in ancient semi-natural woodland from digital aerial sensor imagery. Ecological Applications Vol. 15(4), pp. 1233-1244.

Geomatica, 2013.GeomaticaOrthoEngineOrthorectifying WV-1 and WV-2 Data Rigorous and RPC Modelling.Geomatica 2013 Tutorial.

Gilmore, M.S., Wilson, E.H., Barrett, N., Civco, D.L., Prisloe, S., Hurd, J.D. and Chadwick, C., 2008. Integrating multi-temporal spectral and structural information to map wetland vegetation in a lower Connecticut River tidal marsh. Remote Sensing of Environment Vol. 112, pp. 4048-4060.

Gitelson, A.A., Zur, Y., Chivkunova, O.B. and Merzlyak, M.N., 2002. Assessing catotenoid content in plant leaves with reflectance spectroscopy. Photochemistry and Photobiology Vol. 75 (3), pp. 272281.

Immitzer, M., Atzberger, C. and Koukal, T., 2012. Tree species classification with random forest using very high spatial resolution 8-band Worldview-2 satellite data. Remote Sensing Vol. 4, pp.2661-2693.

Hill, R.A., Wilson, A.K., George, M. and Hinsley, S.A., 2010. Mapping tree species in temperate deciduous woodland using time-series multispectral data. Applied Vegetation Science Vol. 13, pp. 8699.

Van Deventer, H., Cho, M. and Mutanga, O., Do seasonal profiles of foliar pigments improved species discrimination of evergreen coastal tree species in KwaZulu-Natal, South Africa? In Proc. Confer. 35th Int. Symp. Remote Sens. Environ. (ISRSE), 2013 pp. 1-12.

This article was published in JAG: 
Higgins M.A., Asner G.P., Martin, R.E., Knapp, D.E., Anderson, C. Kennedy-Bowdoin, T., Saenz, R., Aguilar, A. and Wright, S.J., 2014.Linking imaging spectroscopy and LiDAR with floristic composition and forest structure in Panama. Remote Sensing of the Environment Vol. 145, pp. 358-367.

Keshava, N., 2004. Distance metrics and band selection in hyperspectral processing with applications to material identification and spectral libraries. IEEE Transactions on Geoscience and Remote Sensing Vol. 42 (7), pp. 1552-1565.

Mudongo, E., Fynn, R., Bonyongo, M.C., 2016. Influence of fire on woody vegetation density, cover and structure at Tiisa Kalahari Ranch in western Botswana. Grassland Science Vol. 62 (1), pp. 3-11.

Mutanga, O. and Skidmore, A.K., 2007. Red edge shift and biochemical content in grass canopies. ISPRS Journal of Photogrammetry \& Remote Sensing Vol. 62 (1), pp. 34-42.

Nacoulma, B., Marie, I., Schumann, K.,Traore, S., Bernhardt-Romermann, M., Hahn, K., Wittig, R. and Thiombiano, A., 2011. Impacts of land-use on West African savanna vegetation: a comparison between protected and communal area in Burkina Faso. Biodiversity and Conservation Vol. 20 (14), pp. 3341-3362.

Nagendra, H., 2001. Using remote sensing to assess biodiversity. International Journal of Remote Sensing Vol. 22 (12), pp. 2377-2400.

Nagendra, H. and Rocchini, D., (2008). High resolution satellite imagery for tropical biodiversity: the devil is in the detail. Biodiversity Conservation Vol. 17, pp. 3431-3441.

Naidoo, L., Cho, M.A., Mathieu, R. and Asner, G., 2012. Classification of savanna tree species in the Greater Kruger National Park region, by integrating hyperspectral and Lidar in a Random Forest data mining environment. ISPRS Journal of Photogrammetry and Remote Sensing Vol. 69, pp.167-179.

Oldeland, J., Dorigo, W., Wesuls, D. and Jürgens, N., 2010. Mapping Bush Encroaching Species by Seasonal Differences in Hyperspectral Imagery. Remote Sensing Vol. 2, pp. 1416-1438.

$\mathrm{Pu}, \mathrm{R}$. and Landry, S., 2012.A comparative analysis of high spatial resolution IKONOS and Worldview2 imagery for mapping urban tree species. Remote Sensing of Environment Vol.124, pp. 516-533.

$\mathrm{Pu}$, R., 2011. Mapping urban forest species using IKONOS imagery: preliminary results. Environmental Management Assessment Vol. 172, pp. 199-214.

Richter, R. and Schlapfer, D., 2012. Atmospheric / Topographic Correction for Satellite Imagery.ATCOR-2/3 User Guide, Version 8.2 BETA.

Shackleton, C.M., Griffin, N.J., Banks, D.I., Mavrandonis, J.M., Shackleton, S.E., 1994.Community structure and species composition along a disturbance gradient in a communally managed SouthAfrican savanna. Vegetatio Vol. 115, 157-167.

Shackleton, C.M. and Shackleton, S., 2003.Value of non-timber forest products and rural safety nets in South Africa. In: Proc. International Conference on Rural Livelihoods, Forests and Biodiversity, Bonn, Germany, 19-23 May, pp. 1-18. 
Shackleton, C.M., Shackleton, S.E., Buiten, E. and Bird, N., 2007.The importance of dry woodlands and forests in rural livelihoods and poverty alleviation in South Africa. Forest Policy and Economics Vol. 9 (5), pp.558-577.

Schlesinger, J.; Drescher, A.; Shackleton, C. M.,2015. Socio-spatial dynamics in the use of wild natural resources: Evidence from six rapidly growing medium-sized cities in Africa. Applied Geography Vol.

56 Pg. 107-115.

Stevens, N., Swemmer, A.M. and Ezzy, L., 2014. Investigating potential determinants of the distribution limits of a savanna woody plant: Colophospermummopane. Journal pf Vegetation Science Vol. 25 (2), pp. 363-373.

Turner, W., Spector, S., Gardiner, N., Fladeland, M., Sterling, E. and Steininger, M., 2003.Remote sensing for biodiversity science and conservation. Trends in Ecology and Evolution Vol. 18 (6), pp. 306-314.

Venter, K.J., Scholes, R.J., \& Eckhardt, H.C. (2003). The abiotic template and its associated vegetation pattern. In J. Du Toit, H. Biggs, \& K.H. Rogers (Eds.), The Kruger experience: Ecology and management of savanna heterogeneity (pp. 83-129). London: Island Press

Wessels, K.J., Mathieu, R., Erasmus, B.F.N., Asner, G.P., Smit, I.P.J., van Aardt, J.A.N., Main, R., Fisher, J. Marais, W., Kennedy-Bowdoin, T.,Knapp, D.E., Emerson, R. and Jacobson, J., 2011. Impact of communal land use and conservation on woody vegetation in the Lowvelsavannas of South Africa. Forest Ecology and Management Vol. 261, pp. 19-29.

Zur, Y., Gitelson, A.A., Chivkunova, O.A. and Merzlyak, M.N., 2000. The spectral contribution of carotenoids to light absorption and reflectance in green leaves. In Proceedings of the $2^{\text {nd }}$ International Conference Geospatial Information in Agriculture and Forestry, Buena Vista, FL, January 10-12. 